\title{
Research and Development in Intelligent Systems XXIII
}


Max Bramer, Frans Coenen and Andrew Tuson (Eds)

\section{Research and Development in Intelligent Systems XXIII}

Proceedings of Al-2006, the Twenty-sixth SGAI International Conference on Innovative Techniques and Applications of Artificial Intelligence

酐 Springer 
Professor Max Bramer, BSc, PhD, CEng, FBCS, FIEE, FRSA

Faculty of Technology, University of Portsmouth, Portsmouth, UK

Dr Frans Coenen, $\mathrm{PhD}$

Department of Computer Science, University of Liverpool, Liverpool, UK

Dr Andrew Tuson, MA, MSc, PhD, MBCS

Department of Computing, City University, London

British Library Cataloguing in Publication Data

A catalogue record for this book is available from the British Library

ISBN-10: 1-84628-662-X

Printed on acid-free paper

ISBN-13: 978-1-84628-662-9

(c) Springer-Verlag London Limited 2007

Apart from any fair dealing for the purposes of research or private study, or criticism or review, as permitted under the Copyright, Designs and Patents Act 1988, this publication may only be reproduced, stored or transmitted, in any form or by any means, with the prior permission in writing of the publishers, or in the case of reprographic reproduction in accordance with the terms of licences issued by the Copyright Licensing Agency. Enquiries concerning reproduction outside those terms should be sent to the publishers.

The use of registered names, trademarks, etc. in this publication does not imply, even in the absence of a specific statement, that such names are exempt from the relevant laws and regulations and therefore free for general use.

The publisher makes no representation, express or implied, with regard to the accuracy of the information contained in this book and cannot accept any legal responsibility or liability for any errors or omissions that may be made.

Printed in the United Kingdom

987654321

Springer Science+Business Media springer.com 


\title{
TECHNICAL PROGRAMME CHAIR'S INTRODUCTION
}

\author{
M.A.BRAMER \\ University of Portsmouth, UK
}

This volume comprises the refereed technical papers presented at AI-2006, the Twenty-sixth SGAI International Conference on Innovative Techniques and Applications of Artificial Intelligence, held in Cambridge in December 2006. The conference was organised by SGAI, the British Computer Society Specialist Group on Artificial Intelligence.

The papers in this volume present new and innovative developments in the field, divided into sections on AI Techniques, Knowledge Discovery in Data, Argumentation, Dialogue Games and Optimisation, Knowledge Representation and Management, Semantic Web, and Model Based Systems and Simulation. For the first time the volume also includes the text of short papers presented as posters at the conference.

This year's prize for the best refereed technical paper was won by a paper entitled Combining Task Execution with Background Knowledge for the Verification of Medical Guidelines' written by a team comprising Arjen Hommersom, Perry Groot and Peter Lucas (University of Nijmegen, The Netherlands) and Michael Balser and Jonathan Schmitt (University of Augsburg, Germany). SGAI gratefully acknowledges the long-term sponsorship of Hewlett-Packard Laboratories (Bristol) for this prize, which goes back to the 1980 s.

This is the twenty-third volume in the Research and Development series. The Application Stream papers are published as a companion volume under the title Applications and Innovations in Intelligent Systems XIV.

On behalf of the conference organising committee I should like to thank all those who contributed to the organisation of this year's technical programme, in particular the programme committee members, the executive programme committee and our administrator Mark Firman.

Max Bramer

Technical Programme Chair, AI-2006 


\section{ACKNOWLEDGEMENTS}

\section{AI-2006 CONFERENCE COMMITTEE}

Dr. Andrew Tuson,

City University

Dr. Tony Allen,

Nottingham Trent University

(Past Conference Chair and Deputy

Dr. Alun Preece,

University of Aberdeen

(Deputy Conference Chair,

Dr Frans Coenen,

University of Liverpool

(Conference Chair)

Application Program Chair)

Electronic Services)

(Deputy Conference Chair, Local

Arrangements and Deputy Technical

Programme Chair)

Prof. Adrian Hopgood,

Nottingham Trent University

(Workshop Organiser)

Rosemary Gilligan

(Treasurer)

University of Hertfordshire

Dr Nirmalie Wiratunga,

The Robert Gordon University, Aberdeen

Richard Ellis,

Stratum Management Ltd

(Poster Session Organiser)

Professor Max Bramer,

University of Portsmouth

(Application Programme Chair)

Alice Kerly

(Research Student Liaison)

University of Birmingham

(Technical Programme Chair)

Dr. Miltos Petridis

University of Greenwich

(UK CBR Organiser)

Mark Firman

(Conference Administrator)

City University

\section{TECHNICAL EXECUTIVE PROGRAMME COMMITTEE}

Prof. Max Bramer, University of Portsmouth (Chair)

Dr. Frans Coenen, University of Liverpool (Vice-Chair)

Mr. John Kingston, University of Edinburgh

Dr. Peter Lucas, University of Nijmegen, The Netherlands

Dr. Alun Preece, University of Aberdeen

Dr. Nirmalie Wiratunga, The Robert Gordon University, Aberdeen 
VIII

\section{TECHNICAL PROGRAMME COMMITTEE}

Alia Abdelmoty (Cardiff University)

Andreas A Albrecht (University of

Hertfordshire)

Tony Allen (Nottingham Trent

University)

Somaya A. S. Almaadeed (Qatar

University)

Roman Belavkin (Middlesex University)

Yaxin Bi (University of Ulster)

Max Bramer (University of Portsmouth)

Krysia Broda (Imperial College, University of London)

Ken Brown (University College Cork)

Frans Coenen (University of Liverpool)

Ernesto Compatangelo (University of Aberdeen)

Bruno Cremilleux (University of Caen)

Madalina Croitoru (University of

Aberdeen, Scotland)

Ireneusz Czarnowski (Gdynia Maritime University, Poland)

Marina De Vos (University of Bath)

John Debenham (University of

Technology; Sydney)

Stefan Diaconescu (Softwin)

Belen Diaz-Agudo (University

Complutense of Madrid)

Nicolas Durand (University of Caen)
Anneli Edman (University of Upsala)

Adriana Giret (Universidad Politécnica de Valencia)

Marco Antonio Gomez-Martin

(University Conmplutense of Madrid)

Nadim Haque (University of

Southampton)

Syed Zahid Hassan (Central Queensland University, Australia)

Adrian Hopgood (The Nottingham Trent University)

Piotr Jedrzejowicz (Gdynia Maritime University; Poland)

Rasa Jurgelenaite (Radboud University, The Netherlands)

Ray Kemp (Massey University, New Zealand)

John Kingston (University of Edinburgh)

Konstantinos Kotis (University of the Aegean)

Ivan Koychev (Bulgarian Academy of Science)

T. K. Satish Kumar (University of California, Berkeley)

Peter Lucas (University of Nijmegen)

Daniel Manrique Gamo (University of Madrid)

Raphaël Marée (University of Liege; Belgium) 
Alfonsas Misevicius (Kaunas University of Technology)

Emma-Claire Mullally (National

University of Ireland)

David Muse (University of Sunderland)

Lars Nolle (Nottingham Trent

University)

Tomas Eric Nordlander (University

College Cork)

Dan O'Leary (University of Southern

California)

Barry O'Sullivan (University College Cork)

Alun Preece (University of Aberdeen)

Juan Jose Rodriguez (University of Burgos)

Maria Dolores Rodriguez-Moreno

(Universidad de Alcala)

Miguel A. Salido (Universidad

Politécnica de Valencia)

Rainer Schmidt (University of Rostock, Germany)
Evgueni Smirnov (Maastricht

University, The Netherlands)

Fernando Saenz Perez (Universidad

Complutense de Madrid)

Fadi Thabtah (University of Huddersfield)

Jon Timmis (University of York)

Gianluca Torta (Università di Torino)

Andrew Tuson (City University)

M.R.C. van Dongen (University College Cork)

Marcel van Gerven (Radboud

University, The Netherlands)

Graham Winstanley (University of Brighton)

Nirmalie Wiratunga (Robert Gordon University)

Fei Ling Woon (University of Greenwich 


\section{CONTENTS}

\section{BEST TECHNICAL PAPER}

Combining Task Execution and Background Knowledge for the Verification of Medical Guidelines ( $x$ )

Arjen Hommersom, Perry Groot, Peter Lucas (University of Nijmegen, The Netherlands), Michael Balser and Jonathan Schmitt (University of Augsburg,

Germany)

\section{SESSION 1: AI TECHNIQUES (GAs, BIO-MOTIVATED COMPUTING AND BAYES)}

A Discrete Particle Swarm Optimization Algorithm for the Permutation Flowshop Sequencing Problem with Makespan Criterion Quan-Ke Pan (Liaocheng University, China), M.Fatih Tasgetiren (Fatih University, Turkey), Yun-Chia Liang (Yuan Ze University, Taiwan)

Intialization Method for Grammar-guided Genetic Programming $(x)$

Marc Garcia-Arnau, Daniel Manrique, Juan Rios and Alfonso Rodriguez-Paton (U. Politecnica Madrid, Spain)

Improving the Gradient Based Search Direction to Enhance Training Efficiency of Back Propagation Based Neural Network Algorithms Nazri Mohd Nawi, Meghana R. Ransing and Rajesh S. Ransing (University of Wales, UK)

A Decision Tree-Based Attribute Weighting Filter for Naive Bayes $(x)$ Mark Hall (University of Waikato, New Zealand)

Graphical Reasoning with Bayesian Networks Ildiko Flesch and Peter Lucas (Radboud University Nijmegen, Netherlands)

\section{SESSION 2a: KNOWLEDGE DISCOVERY IN DATA}

Ranked Multi-label Rules Associative Classifier

Fadi Thabtah (University of Huddersfield, UK)

Two Different Approaches to Automated Mark Up of Emotions in Text Virginia Francisco, Raquel Hervás and Pablo Gervás (Universidad Complutense de Madrid, Spain) 
Towards a Framework for Change Detection in Data Sets

Mirko Bötthcer, Detlef Nauck, Dymitr Ruta and Martin Spott (British Telecom).

Incremental Inductive Learning in a Constructivist Agent

Filipo Studzinski Perotto and Luis Otavio Alvares (UFRGS, Brazil)

\section{SESSION 2b: ARGUMENTATION, DIALOGUE GAMES AND OPTIMISATION}

Argument Based Contract Enforcement

Nir Oren, Alun Preece and Timothy J. Norman (University of Aberdeen, UK)

Negotiating Intelligently

John Debenham and Simeon Simoff (University of Technology, Sydney,

Australia)

Avoiding Long and Fruitless Dialogues in Critiquing

David McSherry (University of Ulster, UK) and David W. Aha (Naval

Research Laboratory, USA)

LSA-based Landscape Analysis for Multicast Routing Mohammed S. Zahrani (University of Hertfordshire, UK), Martin J. Loomes (Middlesex University, UK), James A. Malcolm and Andreas A. Albrecht (University of Hertfordshire, UK)

\section{SESSION 3: KNOWLEDGE REPRESENTATION AND MANAGEMENT}

Dependent Record Types for Dynamic Context Representation

Richard Dapoigny and Patrick Barlatier (University of Savoie, France)

Adjusting game difficulty level through Formal Concept Analysis

Marco A. Gómez-Martín, Pedro P. Gómez-Martín, Pedro A. González-Calero

and Belen Díaz-Agudo (Universidad Complutense De Madrid)

Ontology Constraint Satisfaction Problems using Conceptual Graphs

Madalina Croitoru and Ernesto Compatangelo (University of Aberdeen, UK)

Integrating Uncertain Knowledge in a Domain Ontology for Room Concept

Classifications

Joana Hois, Kerstin Schill and John A. Bateman (University of Bremen,

Germany) 


\section{SESSION 4: SEMANTIC WEB}

Using AI and Semantic Web Technologies to attack Process Complexity in Open Systems $(x)$

Simon Thompson, Nick Giles, Yang L,i Hamid Ghari and Thuc Nguyen (BT)

A Semantic Web Blackboard System

Craig McKenzie, Alun Preece and Peter Gray(University of Aberdeen, UK)

Planning with the Semantic Web by fusing Ontologies and Planning Domain Definitions

Marco Cioffi and Simon Thompson (BT)

A Reusable Commitment Management Service using Semantic Web

Technology $(x)$

Alun Preece, Stuart Chalmers and Craig McKenzie (University of Aberdeen,

$U K)$

\section{SESSION 5: MODEL BASED SYSTEMS AND SIMULATION}

On-Line Monitoring of Plan Execution: a Distributed Approach $(\times)$

Roberto Micalizio and Pietro Torasso (Universita' di Torino, Italy)

Incremental Fault Isolation for Dynamic Processes

George Coghill (University of Aberdeen, UK), Guofu Wu (Icom Innovations,

$U K)$

Qualitative Approaches to Semantic Scene Modelling and Retrieval

Zia Ul Qayyum and A.G. Cohn (School of Computing, University of Leeds,

$U K)$

A Platform for Simulating Language Evolution

Carl Vogel and Justin Woods (Trinity College Dublin)

\section{SHORT PAPERS}

Improving the Interpretability of Classification Rules in Sparse Bioinformatics Datasets

James Smaldon and Alex A. Freitas (University of Kent, UK)

An Agent-Based Approach to Non-Distributed and Distributed Clustering Ireneusz Czarnowski and Piotr Jedrzejowicz (Gdynia Maritime University, Poland) 
XIV

Transparency of Computational Intelligence Models

Peter Owotoki and Friedrich Mayer-Lindenberg (TU Hamburg-Harburg,

Germany)

Exploring Web Search Results Clustering

Xiaoxia Wang and Max Bramer (University of Portsmouth, UK)

Case-based Intention Selection for Autonomous Agent that Acts in Structured

Synthetic Worlds

Haris Supic (University of Sarajevo, Bosnia and Herzegovina)

On Clustering Attribute-oriented Induction

Maybin Muyeba, M.Sulaiman Khan and Zhiguo Gong (Liverpool Hope

University, UK)

Chinese Text Clustering for Topic Detection Based on Word Pattern Relation

Yen-Ju Yang and Su-Hsin Yu (Tatung University, Taiwan)

Text Classification Using Language Independent Pre-processing

Yanbo J. Wang, Frans Coenen, Paul Leng and Robert Sanderson (University of Liverpool, UK)

Author Index

Note: $\times$ indicates SGAI recognition award 